\title{
Selection of micro-fabrication techniques on stainless steel sheet for skin friction
}

\author{
S. ZHANG ${ }^{1, *}$, X. ZENG $^{1,2}$, D. T. A. MATTHEWS ${ }^{3}$, A. IGARTUA ${ }^{4}$, E. RODRIGUEZ-VIDAL ${ }^{4}$, J. CONTRERAS FORTES $^{5}$, \\ V. SAENZ DE VITERI ${ }^{4}$, F. PAGANO ${ }^{4}$, B. WADMAN ${ }^{6}$, E. D. WIKLUND ${ }^{6}$, E. VAN DER HEIDE ${ }^{1,7}$ \\ ${ }^{1}$ Laboratory for Surface Technology and Tribology, Faculty of Engineering Technology, University of Twente, Drienerlolaan 5, Enschede \\ $7522 \mathrm{NB}$, the Netherlands \\ ${ }^{2}$ Shanghai Advanced Research Institute, Chinese Academy of Sciences, Shanghai 201210, China \\ ${ }^{3}$ Tata Steel, Research \& Development, Ijmuiden 1970 CA, the Netherlands \\ ${ }^{4}$ IK4-Tekniker, C/Ignacio Goenaga 5, Eibar 20600, Spain \\ ${ }^{5}$ Acerinox Europa SAU, Los Barrios, Spain \\ ${ }^{6}$ Swerea IVF, Argongatan 30, Molndal 43153, Sweden \\ ${ }^{7}$ TU Delft, Faculty of Civil Engineering and Geosciences, Stevinweg 1, Delft 2628 CN, the Netherlands \\ Received: 06 April 2016 / Revised: 09 May 2016 / Accepted: 18 May 2016 \\ (C) The author(s) 2016. This article is published with open access at Springerlink.com
}

\begin{abstract}
This review gives a concise introduction to the state-of-art techniques used for surface texturing, e.g., wet etching, plasma etching, laser surface texturing (LST), 3D printing, etc. In order to fabricate deterministic textures with the desired geometric structures and scales, the innovative texturing technologies are developed and extended. Such texturing technology is an emerging frontier with revolutionary impact in industrial and scientific fields. With the help of the latest fabrication technologies, surface textures are scaling down and more complex deterministic patterns may be fabricated with desired functions, e.g., lotus effect (hydrophobic), gecko feet (adhesive), haptic tactile, etc. The objective of this review is to explore the surface texturing technology and its contributions to the applications.
\end{abstract}

Keywords: microfabrication; surface texturing

\section{Introduction}

Surface texturing is a well-known engineering technology for enhancing the tribological properties of mechanical components, i.e., wear resistance and friction reduction, and for creating lubricant reservoirs or pockets, see Refs. [1-7]. The functionality of the engineered surfaces defines specific characteristics of the surface texturing process, such as enhancing the lifetime of bearing components [8], or increasing formability of steel [9]. With the development of new and existing fabrication technologies, surfaces with detailed micro-topography can be fabricated as

* Corresponding author: S. ZHANG.

E-mail: s.zhang@utwente.nl micro-pits or grooves to effectively improve the tribological properties [10]. As the surface texturing techniques developed and expanded over the years, the functionality of surface topography can be further comprehended and more applications appeared [11-13]. As the result, the textures are scaling-down further and more complex structures can be produced for broader applications, including skin friction and tactility [14, 15].

In the field of tactile perception, a substantial amount of work was conducted to understand how people explore and perceive the textured counter-surface by exploring with the finger pads [16]. Klatzky and Lederman [17] studied the geometric properties of sandpaper-surfaces based on the roughness perception while measuring behavioral and neurophysiological responses. In the work of Skedung et al. [18], finger 
friction measurements are evaluated to determine the relationship between the coefficient of friction (COF) and surface roughness of a series of printing papers. Furthermore, Skedung et al. [19] investigated the relationship between the perceptual dimensions and the implicated physical dimensions on the microstructured polydimethylsiloxane (PDMS) samples, and found that people are capable of dynamically detecting surface structures with wavelength of $760 \mathrm{~nm}$ and amplitude of $13 \mathrm{~nm}$. From the tribological perspective, the parameters of surface texture including spacing, amplitude and waviness are influential factors in skin tribology. The required levels for a polymeric surface can be seen from Fig. 1. The work of Tomlinson et al. [20] found that adhesion component of friction is the predominant mechanism for samples with shallow ridges of a height lower than $42.5 \mu \mathrm{m}$. However, with greater height, the skin penetration to the texture ridges increases the amount of hysteresis friction. Same phenomena are found for the width and size of the ridges.

\section{Skin tribology}

Skin tribology is a relatively new branch of tribologythe science and technology of interacting surfaces
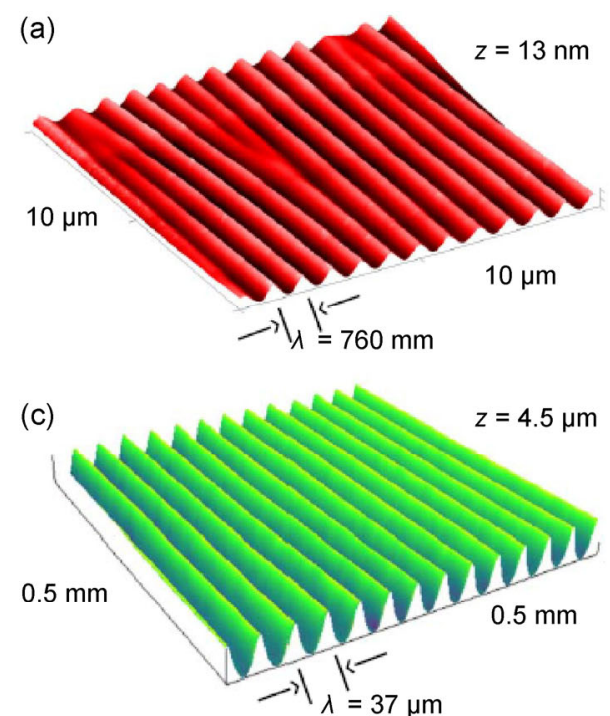

(e)
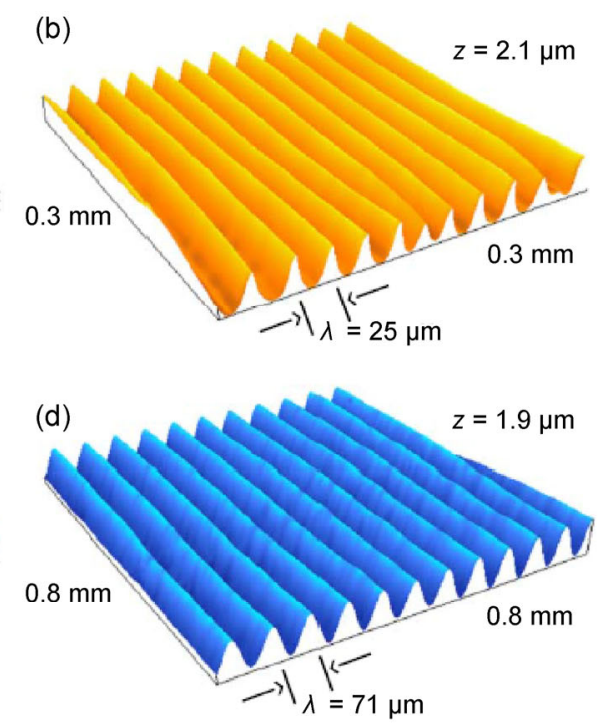

$$
\lambda=0 \mu \mathrm{m}
$$

Fig. 1 Wrinkled-patterned polymeric surfaces with textures for touch perception ranging from nanometers to micrometers [19].

in relative motion-and the human skin is always one of the interacting surfaces. The human skin is a multi-layered living material mainly composed of epidermis, dermis and hypodermis. The stratum corneum, the outmost layer of epidermis, is the shield protecting the entire human body from the surrounding environment. Since it is directly in contact with the counter-body, therefore, it serves an important role in hydration control and in tactile friction. Sensory receptors lay in the layer of dermis which has a role in the tribological response. For the layer of hypodermis, which is the deepest layer of human skin, has the least influence in skin mechanical properties compared to the other layers. Overall, the skin behaves in viscoelastic, non-homogeneous and anistropic manner under load. In addition, many factors including the body site, age, hydration level and perhaps nutritional conditions can affect the tribological behaviour of skin, see the work of Veijgen [21]. The dynamic friction generated between the skin and counter-surface is a tangential force resisting the moving motion. The skin friction is related to the deformation of the bodies in contact and generated in breaking the adhesive bonds between the skin and counter-surface in the microcontacts. It depends on the factors including the operational conditions, material properties, surface

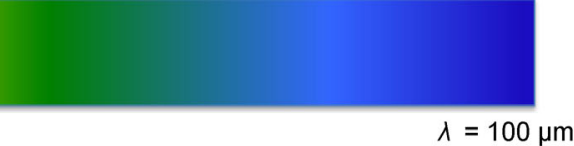


structures and environmental conditions (refer to Fig. 2), reflecting the dependence of friction on the tribological system.

In vivo skin friction measurements were carried out by many researchers, and friction generated between the skin and the counter-surface could be categorized based on the results into two main components: deformation component of friction and the adhesion component of friction [22]. The adhesion component of friction plays the dominant role for both dry and humid conditions in sliding contacts between skin and other surfaces [23,24]. Most experiments are conducted based on skin in dry conditions, because most sliding touches for consumers' products occur in dry conditions. From the mechanical point of view, the real contact area is an important factor in the skin friction, especially the adhesion component of friction. According to the research, skin friction decreases with the reduction of the real contact area [15] just as for other systems where the adhesive component of friction is dominant [25].

$$
F_{\mathrm{f}, \text { adh }}=\tau A_{\text {real }}
$$

where $F_{\mathrm{f}, \text { adh }}$ represents the adhesion component of friction; $A_{\text {real }}$ is the real contact area; $\tau$ is the interfacial shear strength. For the interfacial shear strength $\tau$, it has been found to have a linear function of the average contact pressure $(\bar{p})$ as:

$$
\tau=\tau_{0}+\alpha \bar{p}
$$

where $\tau_{0}$ is the intrinsic interfacial shear strength; $\alpha$ is the pressure coefficient. After combining Eqs. (1) and (2), the coefficient of friction can be expressed as following:

$$
\mu=\frac{F_{\mathrm{f}, \mathrm{adh}}}{F_{\mathrm{N}}}=\frac{\tau}{\bar{p}}=\frac{\tau_{0} A_{\mathrm{real}}}{F_{\mathrm{N}}}+\alpha
$$

The adhesion component of friction is directly related to the real contact area, and the reduction of real contact area is expected to greatly decrease friction. Therefore, the surface texture plays an important role in the tactile friction. With pre-defined deterministic surface texture, the friction generated between the skin and micro-structured counter-surface can be manipulated. Before designing any geometric structures with desired

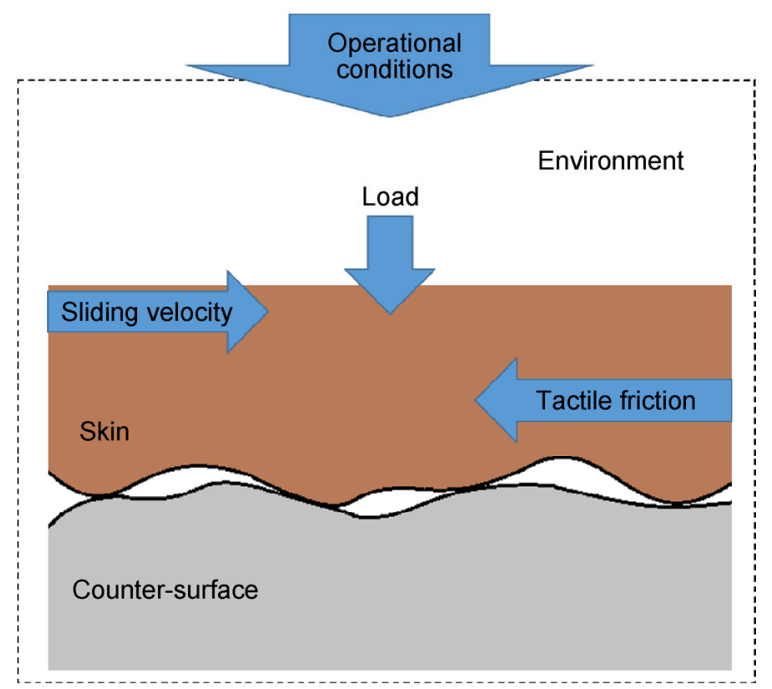

Fig. 2 Tribological system of skin friction.

functionality on the stainless steel sheet, the knowledge of basic concepts and feasibility of the micro-fabrication techniques that allow for predefined, deterministic textures, are important. As the spine of texture design, various surface texturing techniques have to be discussed and studied. In the following sections, the core texturing techniques for deterministic textures at the required scale are introduced from retrospective to the state-of-art, and finally the best suitable fabrication technique will be selected to produce the designed deterministic micro-structures on stainless steel sheet samples.

\section{Micro-fabrication techniques}

\subsection{Micro-casting}

Casting is one of the key fabrication techniques for manufacturing and generally known as lost-mold technique by using a textured mold with materials melt into it $[26,27]$. First, the mold texture needs to be produced by other micro-fabrication techniques including laser surface texturing, 3D printing and other various micro-fabrication techniques in order to create the deterministic pattern. In general, the plastic or wax pattern is produced and embedded in a ceramic slip. The dried mold will be filled with melt materials, and the pattern will be lost due to melting and burning and transfer the texture to the filling materials. After solidification, the mold is mechanically removed without damaging the cast surface. Depending 
on the casting and mold materials, additional chemical cleaning processes may be applied as an extra step.

This technique has been successfully applied for micro-fabricating miniaturized devices for mechanical engineering and bio-mimic duplication [28, 29]. For example of fabricating complicated metal microcomponents, the group of $\mathrm{Li}$ et al. successfully produced a three-dimensional Zn-Al4 alloy microgear including one gear panel and two gear shafts by using metal mold micro-scale precision casting method [30]. Another study uses micro-casting technique to replicate the surface microstructures that contributes to the lotus leaf effect-superhydrophobicity [31]. The lotus surface is directly replicated via a two-stage (negativepositive) direct micro-casting method using three different materials: vinyl polysiloxane (VPS), polydimethylsiloxane (PDMS) and polymethylmethacrylate (PMMA). During the fabrication process, a negative template with the microstructures of lotus leaf was made first by pouring VPS directly onto a section of the lotus lead. After peeled off the lotus leaf, a positive template was created by pouring PDMS onto the cured negative template (refer to Fig. 3). The same process was used to fabricate PDMS-PMMA replicates. Under the pattern examination, VPS-PMMA and PDMS-PMMA replicates display shorter peak heights and larger base widths with contact angles of $132.1^{\circ}$ and $129.2^{\circ}$ respectively.

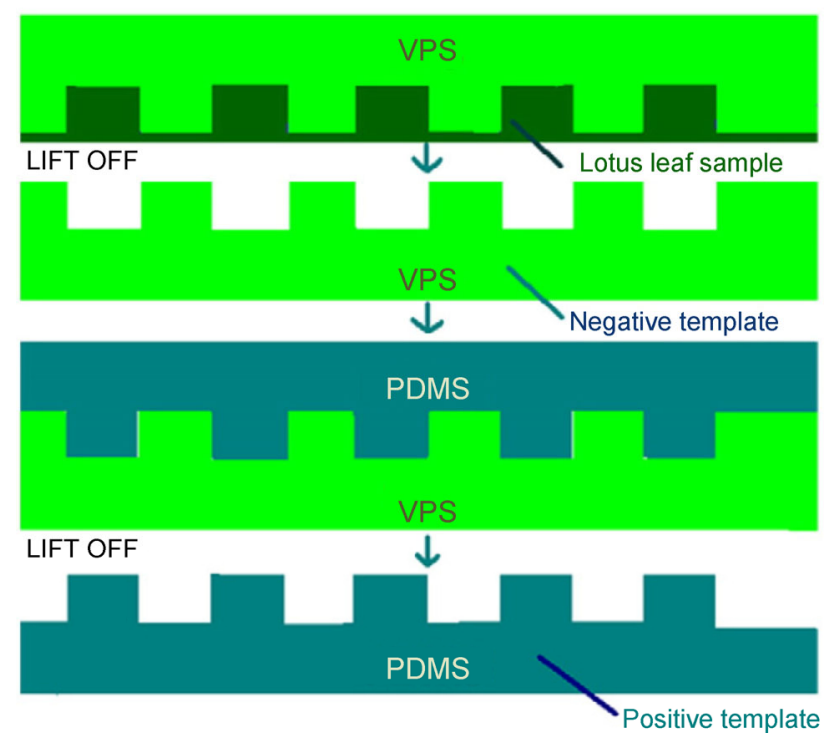

Fig. 3 Schematic illustration of direct replication and process sequence [31].

\subsection{Chemical wet etching}

Wet etching, also known as chemical wet etching or liquid etching, uses liquid chemicals or etchants to perform a material removal process on the sample [32-34]. The predefined masks with desired textures are attached to the sample surface before the chemical wet etching process. Usually, these masks are prefabricated by using lithography technique [35]. During the etching process, the surface regions not covered by the masks are etched away to produce deterministic textures. Meanwhile, multiple chemical reactions are performed which involve three steps: diffusion of the etchant to the material surface which is not covered by the mask; the chemical reactions between the etchant and the materials have been etched away; Secondary diffusion of the reacted sample surface.

Chemical wet etching methods can be categorized into two types: anistropic and isotropic [36, 37]. Both processes have different etching rates which depend on the material properties of the sample. The most common application of anistropic wet etching method is applied for the fabrication of crystalline materials $[38,39]$. The etching rate varies base on the plane of the crystalline material and the concentrations of the etchants. For instance, crystalline material like silicon may have high anisotropic effect by using etchants, e.g., potassium hydroxide $(\mathrm{KOH})$, ethylenediamine pyrocatechol (EDP), tetramethylammonium hydroxide (TMAH), etc. The typical applications for anisotropic wet etching are J-FET arrays, solar cell anti-reflecting surfaces and waveguides.

In 1983, a series of electrochemical measurements of $n$ - and p-type Si wafers with crystal plane of $\left\{\begin{array}{lll}1 & 0 & 0\end{array}\right\}$ and $\left\{\begin{array}{lll}1 & 1 & 1\end{array}\right\}$ were analyzed to study the importance of the orientation dependent etching [40]. Potassium hydroxide $(\mathrm{KOH})$ was used as etchant for the anisotropic wet etching process. Researcher [41] attempted to study the reaction mechanism and key features of all alkaline anisotropic etchants upon silicon materials. In the study, experimental data were analyzed base on the anisotropy, selectivity and voltage dependence of anisotropic etchants. In the conclusion, the concentration of molar water and $\mathrm{pH}$ value are the two key parameters for the etching behaviour of alkaline solutions. In 1995, a research group in IBM's Microelectronics Division, USA [42], was using an etchant 
consisting of ethanolamine, gallic acid, surfactant, catalyst and water for anistropic wet etching on the three major crystal planes of silicon. The objective was to study the catalytic control of anisotropic wet etching rate. During the experiments, chemical etching method was strongly influenced by a variety of oxidative catalysts. The results were categorized into three groups by how fast catalysts can accelerate the chemical etching rate of a specific crystal plane compared to the uncatalyzed rate: two to five times; less than twice and below the uncatalyzed level.

Different from anisotropic wet etching process, the etching rate is same in all direction for isotropic wet etching [43]. It is suitable for removal of predamaged surfaces, rounding of pre-etched sharp corners, fabricating the structures on single-crystal lattices, and producing large geometries. Similar to anisotropic wet etching process, the plane of the crystalline material and the concentrations of etchant are the important factors for etching rate in isotropic wet etching process. The common etchant is the mixture of hydrofluoric acid (HF), nitric acid and acetic acid for crystalline materials. The etching rate is affected by the concentration of each chemical etchant. In some researches, isotropic wet etching was combined with laser surface texturing technique [44]. The concave micro lens arrays were fabricated by a third harmonic Nd: YAG laser on a gold film which coated on a glass substrate. Followed by the isotropic wet etching process, the exposed area on glass substrate was etched by using hydrofluoric acid solutions (refer to Fig. 4). In the study, the effects of various types of HF solutions on etching efficiency were analyzed.

Recently, a research group applied isotropic wet etching technique to fabricate desired texture for light guidance application [36]. HNA based etchant solution is used to produce the surface structure of $300 \mu \mathrm{m}$ deep channel with smooth wall. The etchant composition was selected by surface quality of etching process and etching rate. A spin etcher tool was used to further reduce the surface roughness. This method was able to produce deep isotropic channels in optical quality (refer to Fig. 5).

\subsection{Plasma etching}

Plasma etching is a mature technique specific for the

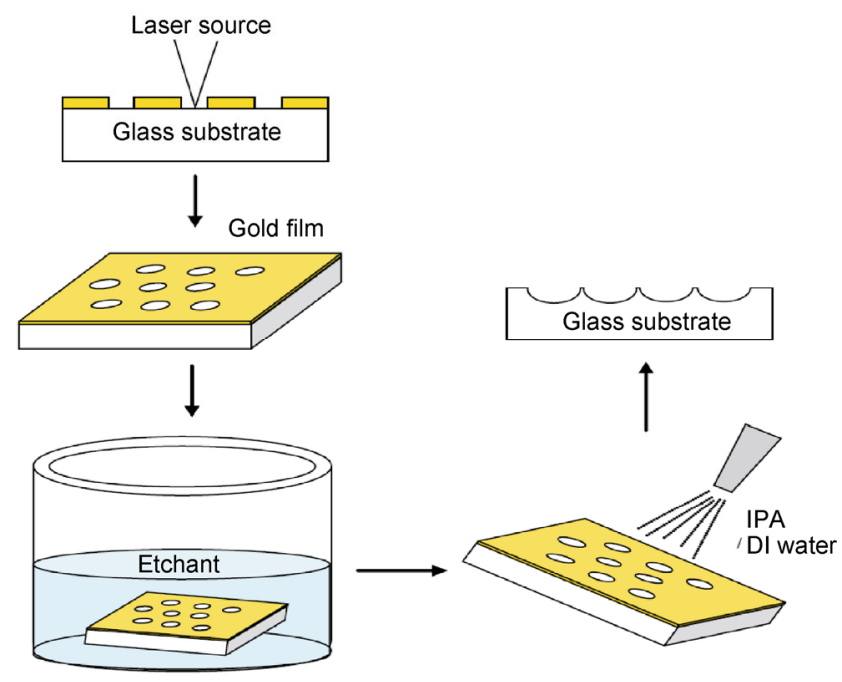

Fig. 4 Schematic of the etching process flow [44].

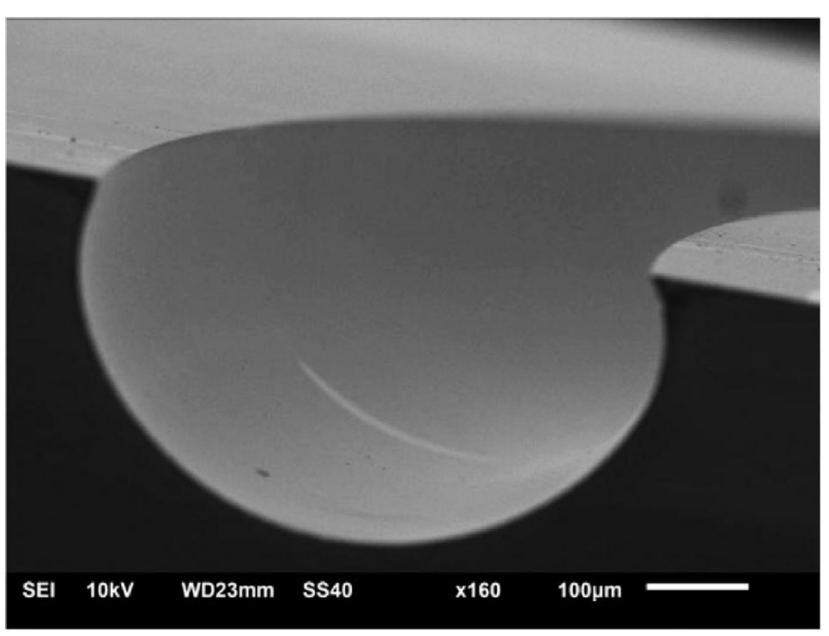

Fig. 5 Image of a $300 \mu \mathrm{m}$ deep channel which has a channel wall in optical quality [36].

fabrication of microsystems and surface texturing [45]. From the mid-1960s, the mechanisms of plasma etching were first introduced as a revolutionary technique for the fabrication of integrated circuit [46]. In the 1970s, it was widely accepted and expected to be an important fabrication technique in the industry of semiconductor and other applications requiring fine-line lithography [47]. In general, plasma etching undergoes a chemical reaction between the solid atoms from the substrate material and gas atoms from the gas etchant. The gas etchants are in the form of molecules, but not chemically reactive enough to fabricate the material surface. The role of plasma is to dissociate the molecules of the gas etchant into reactive atoms in order to be sufficient in the task of 
fabrication. Over the years, various plasma etching techniques are introduced, and radio frequency (RF) sputter etching technique is still the most common and core plasma etching technique for surface texturing.

The radio frequency (RF) sputter etching method was first introduced from IBM [48], and was found to be very useful for fabricating thin film resistors on $\mathrm{Cr}$-SiO films. The $1 \frac{1}{4}$ inch silicon wafers were used as the substrates pre-coated film with a $1.5 \mu$ thickness. Kodak thin film resist (KTFR) was used as the resist through the sputter etching (refer to Fig. 6). From the results, RF sputter etching demonstrated its universality and ability to prevent under-cutting. This technique is able to etch any kinds of substrates with standard photoresist. Later, fluorine and chlorine-containing gas etchants were introduced to RF sputter etching [49]. The compositions of gas etchants are $\mathrm{CF}_{4}, \mathrm{CCl}_{2} \mathrm{~F}_{2}$, $\mathrm{CCl}_{3} \mathrm{~F}, \mathrm{CHCl}_{2} \mathrm{~F}, \mathrm{CHClF}_{2},\left(\mathrm{CCl}_{2} \mathrm{~F}\right)_{2}, \mathrm{CCl}_{2} \mathrm{FCClF}_{2}$ and $\left(\mathrm{CBrF}_{2}\right)_{2}$. The etching rate is enhanced by using fluorine and chlorine-containing gas etchants on $\mathrm{Si}$, quartz, glass, $\mathrm{Al}, \mathrm{Mo}$, stainless steel and photoresist. From the results, RF sputter etching method with fluorine and chlorine-containing gas etchants is characterized as a high rate, precise and dry etching technique.

Recently, the work from Aizawa and Fukuda developed a high-density RF-DC plasma etching system (OXP-1; YS-Electrics, CO. Ltd.) to fabricate the diamond-like carbon (DLC) coating via PVD/CVD on the SKD11 substrate (refer to Fig. 7) [50]. The oxygen gas instead of hazardous etchants such as $\mathrm{CF}_{4}$ was attained with high etching rate. During the etching process, the specimens were fixed on the cathode table before evacuation down to the base pressure of $0.1 \mathrm{~Pa}$. The chamber was filled with a carrier gas to attain the specific pressure. With the use of magnetic
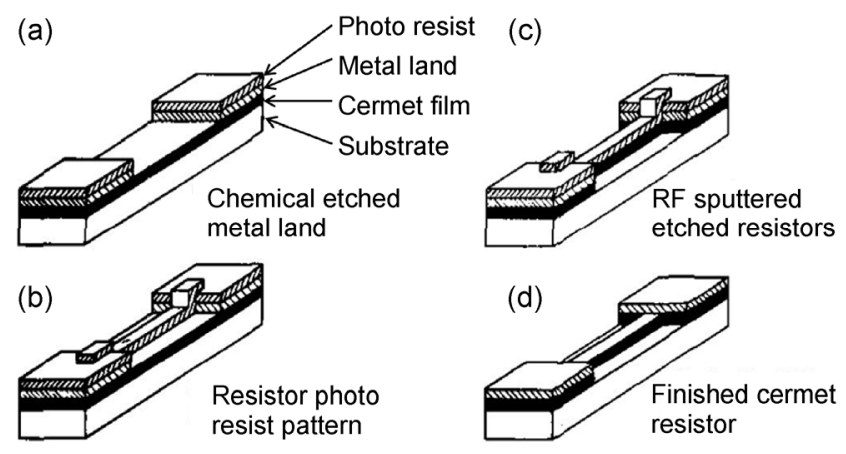

(b)

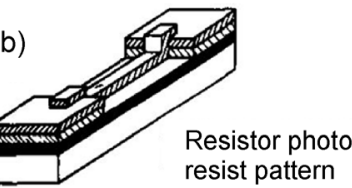

Fig. 6 Sputter-etching of thin-film resistors [48].

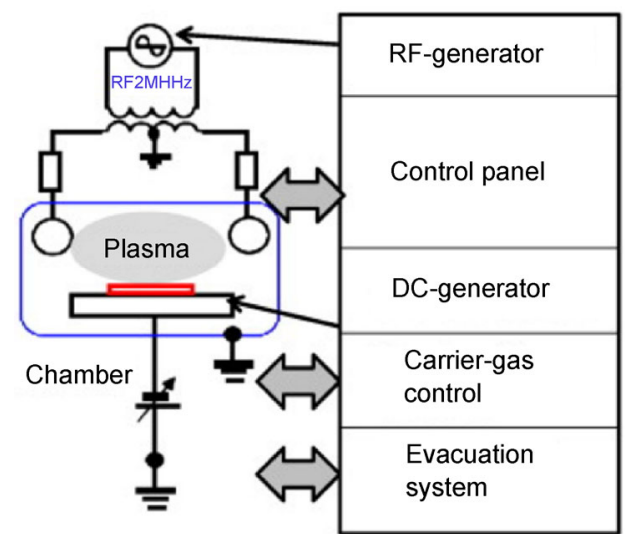

Fig. 7 Schematic diagram of high-density plasma etching system [50].

lens, the ignited RF-DC oxygen plasmas were focused onto the surface of specimens during etching. The RF-voltage, DC bias and pressure were selected to be 250-450 V and 25 to 40 Pa respectively.

\subsection{Three-dimensional printing}

Three-dimensional printing (3DP) is a revolutionary bottom-up fabrication technique. Compared to traditional top-down fabrication techniques, it has many advantages like moldless production, cheap manufacturing, less waste and the ability to produce complex structures. The method was introduced by Charles Hull and first known as stereolithography in 1980s [51]. Early 3D printing method spreaded the material powder layer by layer and used binder material printed by ink-jet to selectively bind the powder in order to produce the parts [52]. After all the layers were finished, the unused powder was removed to complete the process (refer to Fig. 8). The parts were designed by CAD with complete freedom in complex geometry, surface texture and material composition. The potential material selection includes any materials which are available in a particle sized powder form, e.g., polymers, metals and ceramics [53-56].

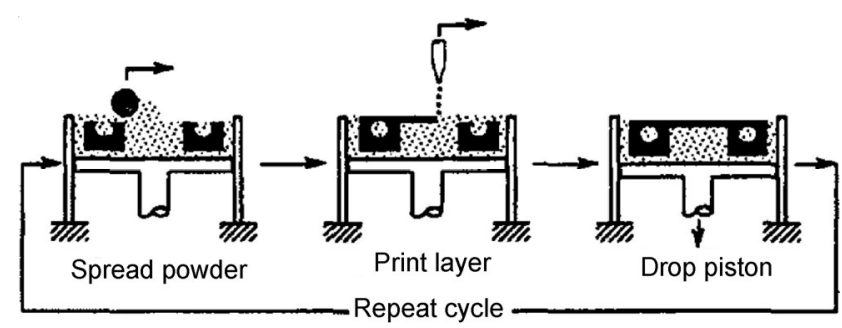

Fig. 8 The sequence of the operations in 3D Printing [52]. 
Recently, a new developed super-resolution 3D printing system was introduced by using electrohydrodynamic (EHD) method [57]. It was able to directly fabricate micro-structures on the substrate surface with phase-change inks. The material of phase-change ink was wax which can be quickly solidified under room temperature after printed onto the substrate surface. The printing system consists of a XYZ precision stage, a thermal control unit, a pneumatic dispensing system and a high voltage supply (refer to Fig. 9). The formation and size of droplet can be predicted by finite element analysis (FEA) model. The EHD 3D printing technique is capable of fabricating high aspect-of-ratio and high resolution (sub-10 $\mu \mathrm{m}$ ) surface structures (refer to Fig. 10).

\subsection{Laser surface texturing}

Laser surface texturing (LST) in particular is regarded as an important technique to enhance tribological performance [58]. Over the decades, many researchers [59-61] studied LST. In 1997, a research group was applying neodymium-yttrium aluminum garnet (NdYAG) pulsed solid-state laser to modify the surface of aluminum alloys [62]. The Nd-YAG laser emitted at a wavelength of $1.06 \mu \mathrm{m}$ and two main surface features were produced: the non-periodic concentric ring structure and the micro-crack pattern. From the experimental results, both ring structure and microcrack could be tailored (pre-defined) to a certain extent in order to improve the adhesive bonding of aluminum alloys. One year later, a research group led by Geiger [63] fabricated microstructures on ceramic surfaces by excimer laser radiation to improve the tribological properties under hydrodynamic and elastohydrodynamic sliding conditions (refer to Fig. 11). Ceramics obtain extremely high hardness, temperature
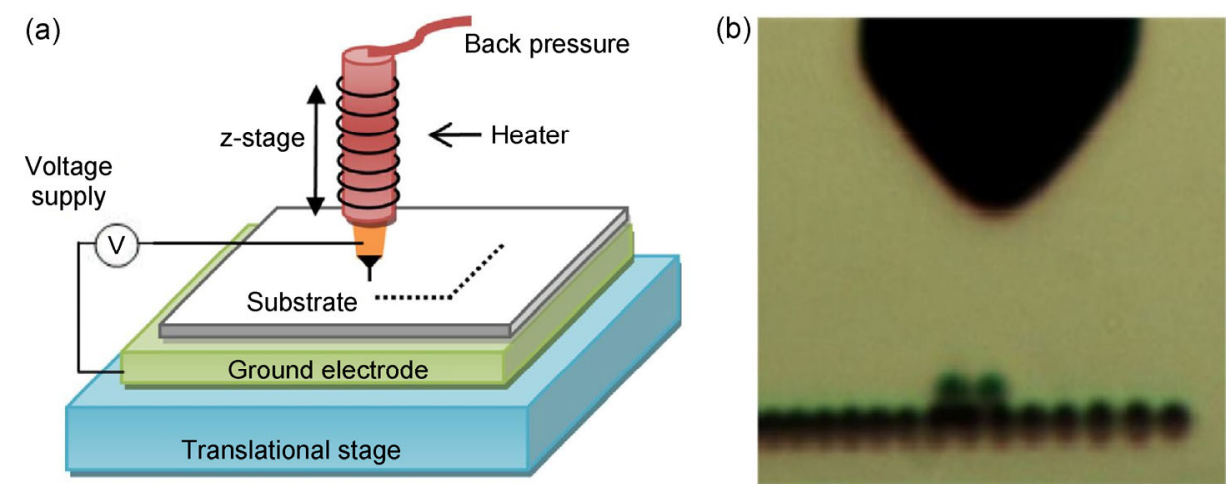

Fig. 9 (a) Schematic of the EHD 3D printing set-up system; (b) pulsating mode of EHD 3D printing of wax [57].
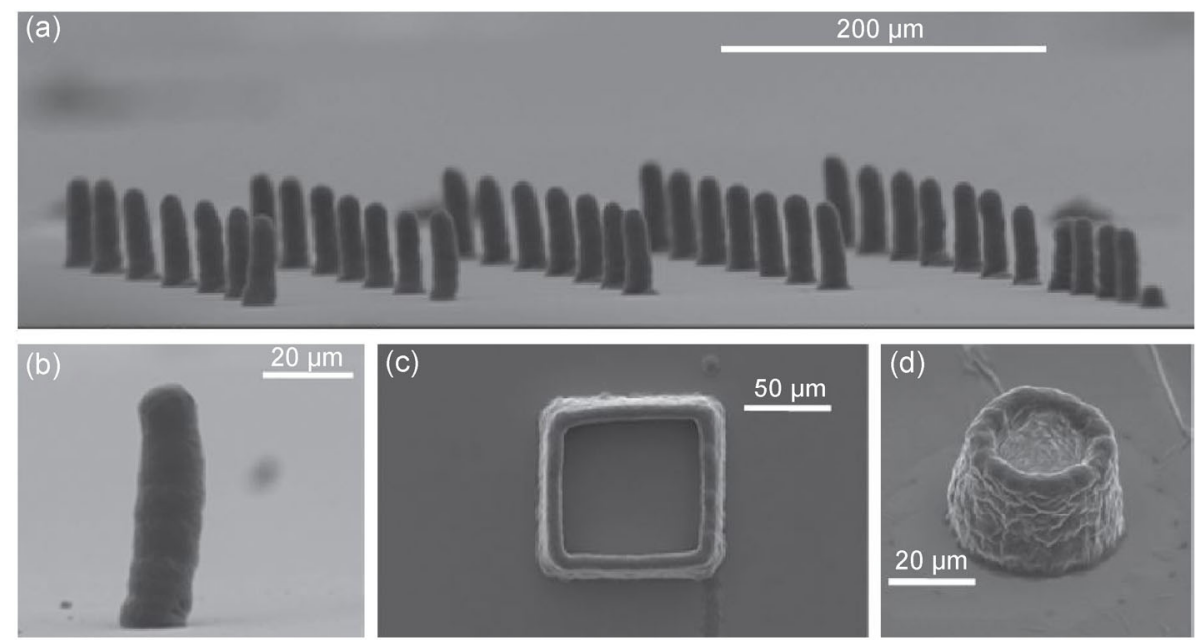

Fig. 10 Micro-structures printed from EHD 3D printing process. (a) Micro-pillar array; (b) close view of a single pillar; (c) square with thin wall; (d) circular tube with thin wall [57]. 

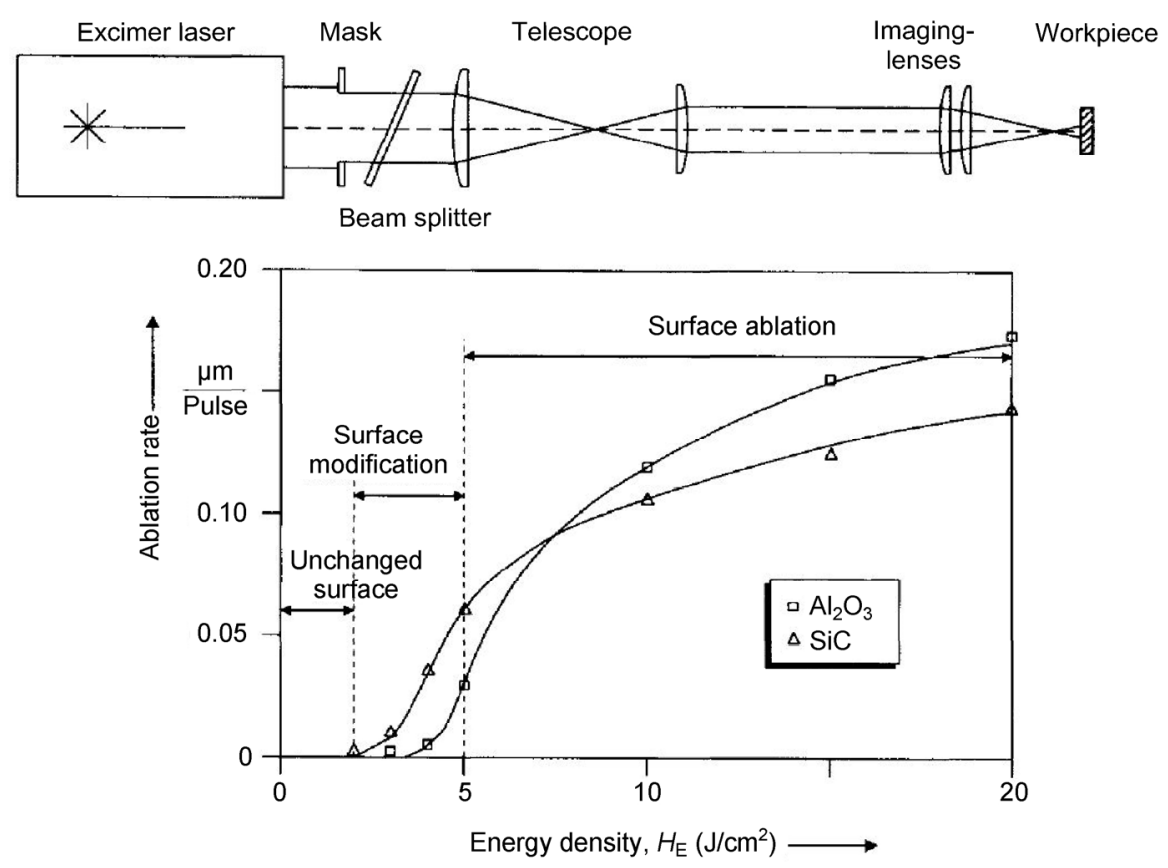

Fig. 11 Micro-structuring of ceramics by $\mathrm{XeCl}$ eximer laser radiation [63].

resistance and corrosion resistance. These material properties made ceramics an excellent choice for the application of wear and sliding. Excimer laser processing offers innovative ways to produce textures on ceramics. Pulsed radiation emitted by excimer lasers are in the UV range of the electromagnetic spectrum. In particular, excimer lasers are effective for fabricating microstructures with high resolution. This is benefitted by the short wavelength $(\lambda=193-351 \mathrm{~nm})$ and small penetration depth of excimer laser radiation. This method is able to modify the surface topography of ceramics by changing surface roughness (Ra), even fabricate microstructures with pre-defined geometric properties to have positive influences on the sliding properties, and increase lubricant film thickness or serve as lubricant reservoirs.

In 2002, the same group [64] was using a mask illuminated by laser beam to project its geometrical information onto the surface (refer to Fig. 12) and

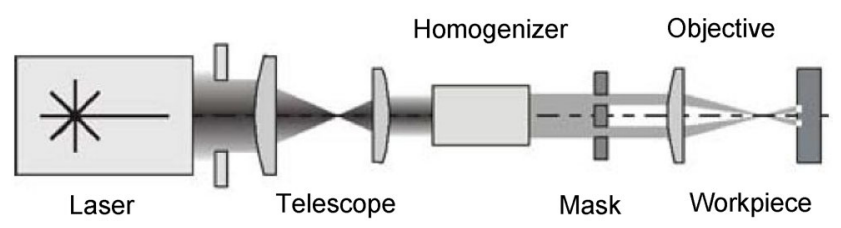

Fig. 12 Principle of the beam guiding system of an excimer laser for use with masks [64]. focusing on the influence of micro textures by excimer laser method on the tribological behaviour of tools in cold forging process. A punch was applied in this method to produce rivets and improve cold forging tool life up to $169 \%$.

$\mathrm{A} \mathrm{CO}_{2}$ laser was used to fabricate micro-pores on $\mathrm{SiC}$ surfaces by a research group in Tohoku University [65]. Various textured specimens fabricated with different intervals between the micro-pores were tested and compared to non-textured specimen (refer to Fig. 13). The effect of the micro-pore area ratio on friction coefficient and the critical load for transition from hydrodynamic to mixed lubrication regime were studied. More extensive research works on LST were done at Argonne National Laboratory, USA [66, 67] to further understand the effect of micro-structures fabricated by LST on the transition from boundary to hydrodynamic lubrication regime. Friction and electrical-contact resistance were measured by a pinon-disk setup in unidirectional sliding conformal contact (refer to Fig. 14). The experimental results illustrated that the range of the hydrodynamic lubrication regime is expanded by LST in terms of load and sliding speed. In addition, micro-dimples produced by LST were able to perform a significant reduction of the friction coefficient compared to non-textured surfaces. 

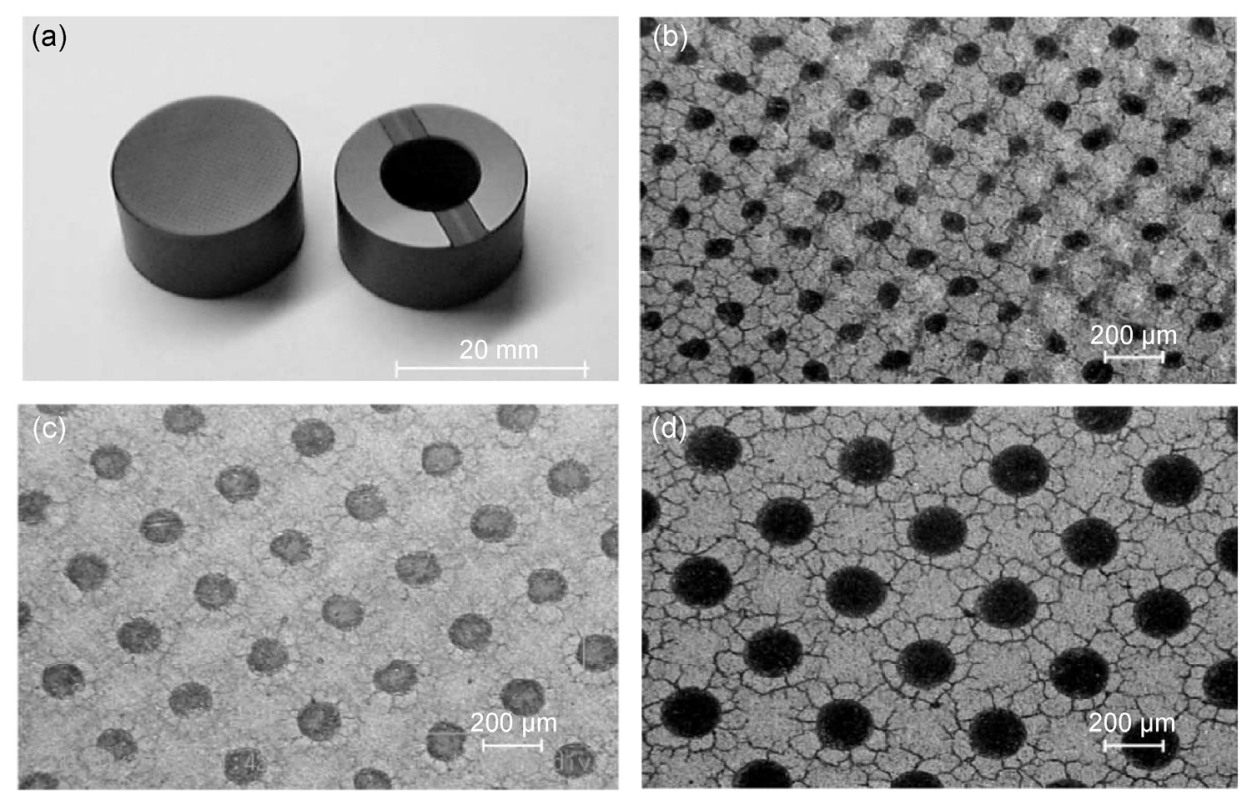

Fig. 13 (a) Appearance of disk (left) and cylinder (right). Optical micrographs of pores on the disk surface produced by laser texturing: (b) the pores with diameter of $100 \mu \mathrm{m}$; (c) the pores with diameter of $150 \mu \mathrm{m}$; (d) the pores with diameter of $200 \mu \mathrm{m}$ [65].
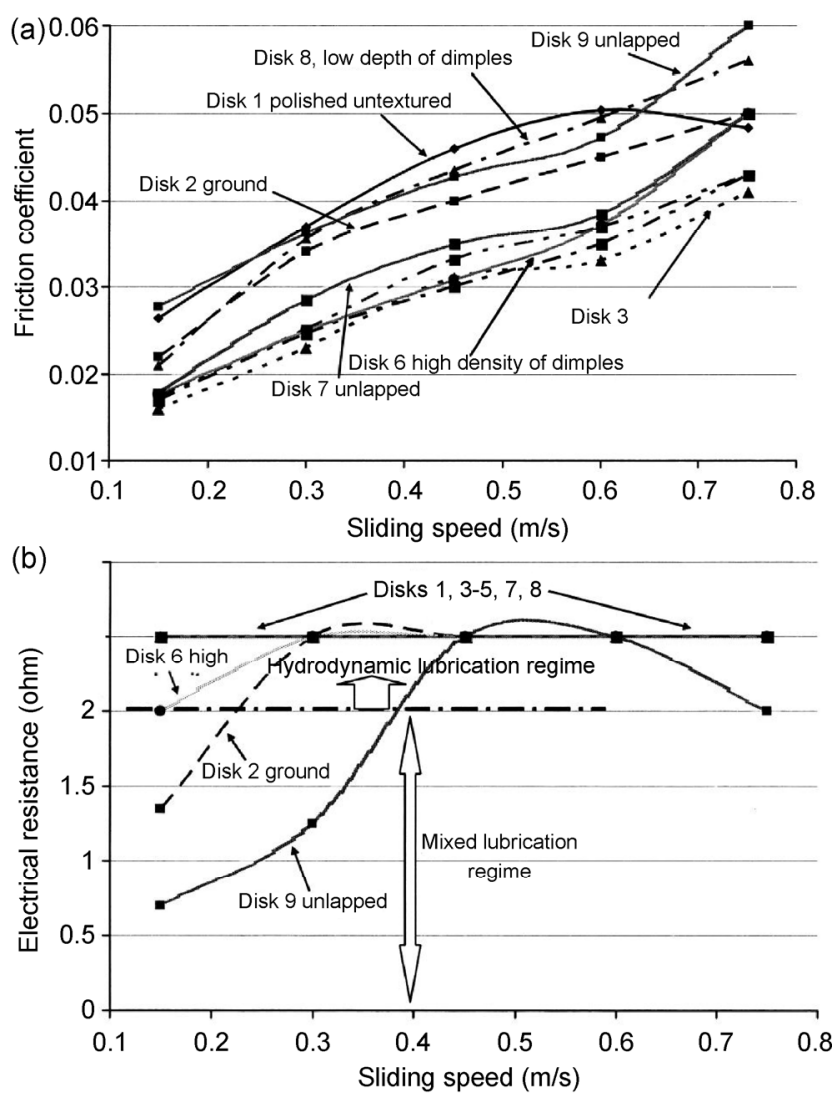

Fig. 14 (a) Friction coefficients; (b) electrical resistance between flat-pin and tested disks as a function of sliding speed at $5 \mathrm{~N}$ load and higher viscosity oil lubricant [66].
Furthermore, the application of LST has been expanded to bio-tribology in the recent years. In the Netherlands, samples with well-defined surface topography were used to unlock the "feel" of surfaces by an experimental study on the relation between surface texture and tactile friction [68]. The microgeometries of the metal samples were fabricated by picosecond laser pulses, also used as injection molds for thermoplastic polyurethane (TPU) samples in experimental work (refer to Fig. 15). Friction measurements of skin against textured samples were carried out by using a load cell (ATI Gamma three-axis force/ torque transducer, ATI Industrial Automation, Apex, NC, USA). Under different normal loads, the coefficient of friction strongly decreased for both textured metal and TPU samples. In the further research, the role of the skin microrelief in the contact between finger and laser textured surfaces was studied [15]. An experimental approach on the friction behavior of the finger pad as a function of asperity geometry was investigated. The surface textures used in vivo testing were fabricated by LST to have evenly distributed asperities with spherical tips. A new multi-scale model was developed to analytically explain skin friction behavior as a function of texture geometry, normal 
(a)

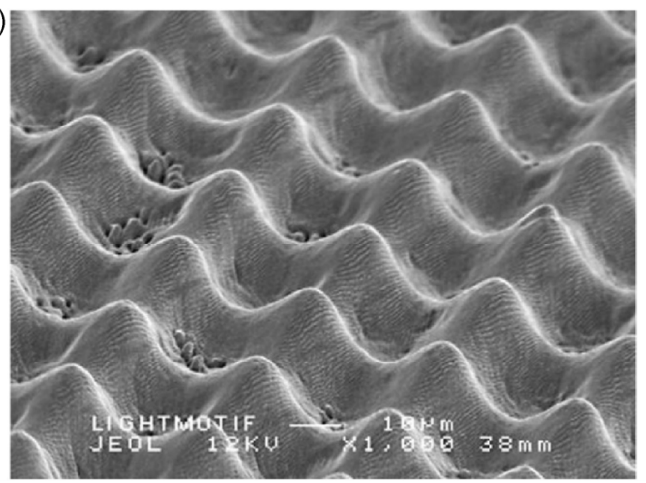

(b)

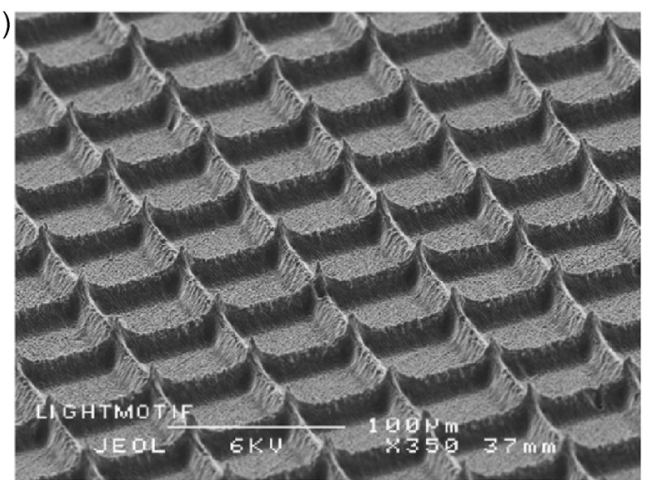

Fig. 15 SEM image (a) metal sample with tip radius $R=5 \mu \mathrm{m}$ and spacing $\lambda=30 \mu \mathrm{m}$; (b) TPU sample with tip radius $R=1 \mu \mathrm{m}$ and spacing $\lambda=60 \mu \mathrm{m}[68]$.

load and skin properties. From the observations of in vivo measurements, the coefficient of friction (COF) was found to increase with the increment of asperity tip radius. With increasing asperity density, COF increased as well. By using relatively simple analytical expressions, the skin friction behavior may be estimated as a function of asperity geometry and operational conditions. Also, LST was proven to be a useful technique to fabricate well-defined micro-textures to study skin-tribology related researches.

\section{Discussion}

It is important to discuss the feasibility of fabrication techniques for stainless steel. From the review of state-of-art fabrication techniques, the pulsed laser surface texturing (LST) is considered as the most suitable method for producing the desired surface structure on the stainless steel sheets (refer to Table 1), i.e., directly by laser ablation. Picosecond and nanosecond lasers can be employed to create specific

Table 1 The advantages and disadvantages of chemical wet etching, plasma etching, LST and 3D printing.

\begin{tabular}{|c|c|c|}
\hline Methods & Advantages & Disadvantages \\
\hline Micro-casting & $\begin{array}{l}\text { - Cheap } \\
\text { - Low cost } \\
\text { - Complex 3D component }\end{array}$ & $\begin{array}{l}\text { - Need other micro-fabrication techniques to produce } \\
\text { the mold }\end{array}$ \\
\hline $\begin{array}{l}\text { Chemical wet } \\
\text { etching }\end{array}$ & $\begin{array}{l}\text { - Low cost, simple process } \\
\text { - Highly selectivity } \\
\text { - Controllable etching rate }\end{array}$ & $\begin{array}{l}\text { - Chemical Contamination } \\
\text { - Orientation dependent (the plane of the crystalline) } \\
\text { - Poor repeatability based on the influences of } \\
\text { temperature and concentration of etchant } \\
\text { - Undercutting. }\end{array}$ \\
\hline Plasma etching & $\begin{array}{l}\text { - High feature resolution } \\
\text { - Easy to control } \\
\text { - High reproducibility } \\
\text { - No liquid chemical waste }\end{array}$ & $\begin{array}{l}\text { - High cost } \\
\text { - Poor selectivity } \\
\text { - Potential radiation damage }\end{array}$ \\
\hline LST & $\begin{array}{l}\text { - Dry process with physical contact } \\
\text { - Automated process } \\
\text { - Precise control of etching depth } \\
\text { - Able to fabricate on metallic workpiece }\end{array}$ & $\begin{array}{l}\text { - time consuming } \\
\text { - high cost }\end{array}$ \\
\hline $3 \mathrm{D}$ printing & $\begin{array}{l}\text { - Complex structures } \\
\text { - Low cost } \\
\text { - Rapid prototyping } \\
\text { - Automated process }\end{array}$ & $\begin{array}{l}\text { - Limited raw materials } \\
\text { - Low feature resolution }\end{array}$ \\
\hline
\end{tabular}


topographic features [69], such as grids (picosecond laser), crater (nanosecond laser), and groove (nanosecond laser) patterns with different surface parameters. Secondly, specific operational conditions can be used for texture design aspects.

However, LST is a rather time consuming and high cost fabrication technique. For this reason, stamping (or pressing) and cold rolling, which are low cost with fast production rate, can be applied for the micro-fabrication with textured stamping dies and textured cold rolling rolls by LST. Full upscaling of the process is required to gauge the applicability of the laser texturing process to industrial stamping die. Primarily, a TUWI compression rig was used for stamping process at Tata Steel (refer to Fig. 16) [69]. In the first stage, the roughness transfer capability needs to be evaluated. After an initial texture pattern was considered, the imprinting tests were carried out. For texturing the cold rolling rolls, a 6-axis robot was used by IK4-TEKNIKER along with a rotary axis during the laser texturing process. Primarily, Tata Steel Pilot Mill (named the MultiMill) (refer to Fig. 17) in 4-high mode was used for the cold rolling. The textured work rolls are driven and supported by back-up rolls. The strip was hand-fed in $150 \mathrm{~mm}$ wide strips with length of $500 \mathrm{~mm}$ to $1,000 \mathrm{~mm}$. As a result, the stainless steel sheet was fabricated with the designed textures by LST, stamping and cold rolling techniques. The surface texture of samples was examined by SEM and confocal microscope (refer to Fig. 18).

The dynamic sliding friction between the skin and samples was measured by a multi-axis force/torque
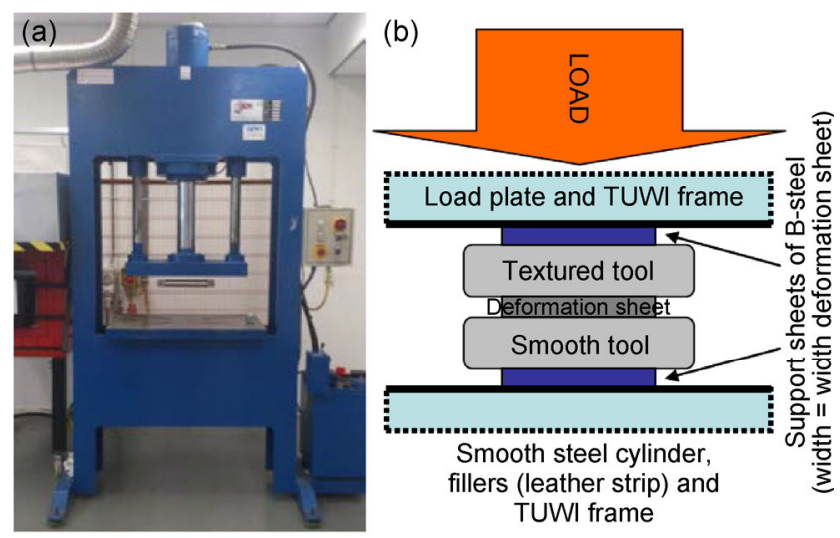

Fig. 16 (a) Overview of the TUWI compression rig used for stamping, and (b) schematic of the key aspects of the set-up at Tata Steel within the STEELTAC project [69].

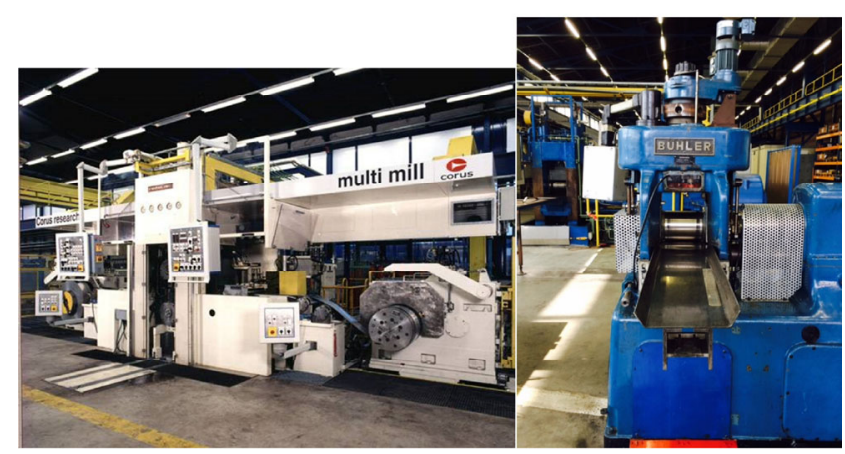

Fig. 17 Overview of the pilot rolling mills at Tata Steel, used for rolling trials in Steeltac: (left) 4-high Multimill, and (right) 2-high "Bühler" mill, used for the STEELTAC project [69].

transducer (ATI Industrial Automation, Apex, NC, USA). One conventionally finished sample (2G finish) was conducted in the same friction measurement as a reference sample for comparison. The testing finger belongs to an adult male (32 year-old) with no-known skin disease. The same finger (middle finger of left hand) was used for all texting samples during the measurements. The stroke length was $30 \mathrm{~mm}$ and the sliding velocity was kept as constant as possible with an average of $44.3 \mathrm{~mm} / \mathrm{s}$.

Base on the results of friction measurements, the average COFs of micro-structured samples with predefined deterministic textures ranged from 1.05 to 1.26 compared to the reference sample with COF of $3.64 \pm 1.04$ (refer to Table 2). As shown in Figs. 19(a)\&(b), the micro-structured samples including laser surface textured, stamped and cold rolled samples significantly decreased the friction force between the skin and counter-surfaces compared to the reference sample. The results validated that the pre-defined deterministic surface textures on stainless steel sheet produced by laser surface texturing, stamping and cold rolling fabrication techniques can greatly influence the friction between the skin and counter-surface, in this case, the skin friction was greatly reduced.

\section{Conclusion}

Micro-casting, chemical wet etching, plasma etching, laser surface texturing and 3D printing are the major fabrication methods to produce predefined deterministic surface structures in micro scale detail. In addition, micro-casting and 3D printing are able to produce complicated 3D components. In comparison, 
(a)

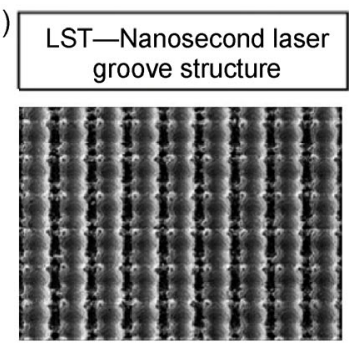

(d)

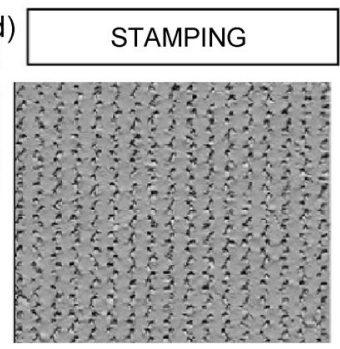

(b)

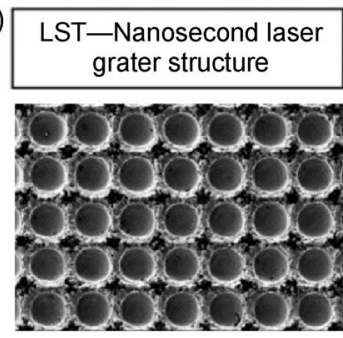

(e)

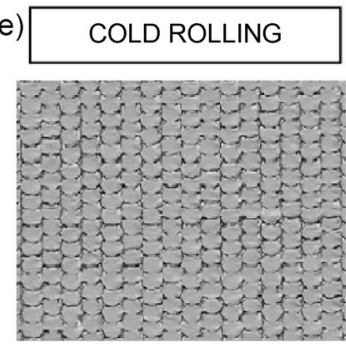

(c)

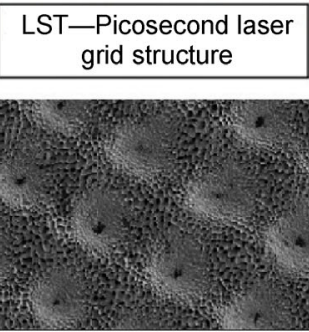

Fig. 18 SEM images of samples (a) crater, (b) groove and (c) grid patterns; confocal microscope image of sample: (d) stamped and (e) cold rolled samples [69].

Table 2 Friction measurements of all samples.

\begin{tabular}{cccc}
\hline Sample name & Normal force $(\mathrm{N})$ & Friction force $(\mathrm{N})$ & COF \\
\hline Groove (NS) & $0.12 \pm 0.03$ & $0.13 \pm 0.03$ & $1.09 \pm 0.09$ \\
Crater (NS) & $0.18 \pm 0.05$ & $0.19 \pm 0.06$ & $1.05 \pm 0.82$ \\
Grid (PS) & $0.13 \pm 0.04$ & $0.15 \pm 0.05$ & $1.26 \pm 0.55$ \\
Crater (Stamped) & $0.16 \pm 0.03$ & $0.19 \pm 0.07$ & $1.23 \pm 0.37$ \\
Crater (Cold Rolled) & $0.18 \pm 0.04$ & $0.21 \pm 0.06$ & $1.18 \pm 0.28$ \\
2G (Reference) & $0.15 \pm 0.04$ & $0.51 \pm 0.16$ & $3.64 \pm 1.04$ \\
\hline
\end{tabular}
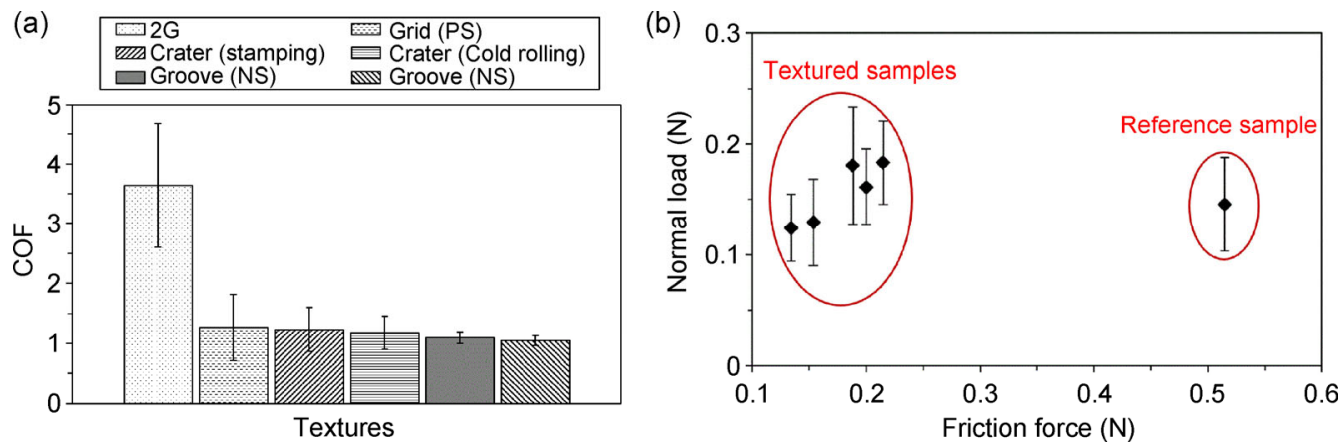

Fig. 19 (a) The average values of COF of the dynamic friction measurements; (b) the average normal load versus friction force.

3D printing is a relatively new method, and its innovative method of bottom-up processing offers the potential to completely revolutionize the process of surface texturing. In this review, the mechanism and application of all five categories of surface texturing techniques are introduced, and each method has its advantages and disadvantages (refer to Table 1). Also, it is important to understand that one method may be more appropriate than the other in a given application or producing a specific surface structure.

The needs for the surface structures in industrial and scientific fields are not stalled, and the surface texturing techniques are always evolving. From chemical wet etching to $3 \mathrm{D}$ printing, or from a 
traditional method to a revolutionary bottom-up rapid processing method, surface texturing techniques are improving and innovating continuously.

In this paper, LST is chosen to be the main fabrication method for producing the surface texture due to its accuracy and ability to fabricate on stainless steel sheet material. For large production, the industrial stamping and cold rolling processes can be used, based on imprinting the negative of the design, to lower the cost and fabrication time. Again, LST has proven its feasibility in creating the negative at the involved forming tools, although only at laboratory scale yet. Based on the friction measurement tests, the predefined deterministic textures greatly reduced the dynamic friction between the skin and microstructured samples compared to the reference sample which has a stochastic surface.

\section{Acknowledgements}

This work was supported by the Research Programme of the Research Fund for Coal and Steel (Contract No. RFSR-CT-2011-00022).

Open Access: The articles published in this journal are distributed under the terms of the Creative Commons Attribution 4.0 International License (http:// creativecommons.org/licenses/by/4.0/), which permits unrestricted use, distribution, and reproduction in any medium, provided you give appropriate credit to the original author(s) and the source, provide a link to the Creative Commons license, and indicate if changes were made.

\section{References}

[1] Wiklund D. Tribology of stamping the influence of designed steel sheet surface topography on friction. PhD Thesis. Chalmers Tekniska Hogskola, Gothenburg, Sweden, 2006.

[2] Pettersson U, Jacobson S. Influence of Surface Texture on Boundary Lubricated Sliding Contacts. Tribol Int 36: 857-864 (2003)

[3] Sugihara T, Enomoto T, Crater and Flank. Wear resistance of cutting tools having micro textured surfaces. Precision Engineering 37(4): 888-896 (2013)

[4] Tang W, Zhou Y K, Zhu H, Yang H F. The effect of surface texturing on reducing the friction and wear of steel under lubricated sliding contact. Appl Surf Sci 273: 199-204 (2013)

[5] Ling F F. Fractals, engineering surfaces and tribology. Wear 136: 141-156 (1990)

[6] Zahouani H, Vargiolu R, Loubet J L. Fractal models of surface topography and contact mechanics. Mathematical and Computer Modelling 28: 517-534 (1998)

[7] Bruzzone A A G, Costa H L. Functional characterization of structured surfaces for tribological applications. Procedia CIRP 12: 456-461 (2013)

[8] Ibatan T, Uddin M S, Chowdhury M A K. Recent development of surface texturing in enhancing tribological performance of bearing sliders. Surf Coat Technol 272: 102-120 (2015)

[9] Wiklund D, Rosen B G, Gunnarsson L. Frictional mechanisms in mixed lubricated regime in steel sheet metal forming. Wear 264: 474-479 (2008)

[10] Groenendijk M N W, Meijer J. Surface microstructures obtained by femtosecond laser pulses. CIRP Annals 55(1): 183-186 (2006)

[11] Yan X, Li W, Aberle G A, Venkataraj S. Investigation of the thickness effect on material and surface texturing properties of sputtered $\mathrm{ZnO}$ :Al films for thin-film Si solar cell applications. Vacuum 123:151-159 (2016)

[12] Khatri B C, Sharma C S. Influence of textured surface on the performance of non-recessed hybrid journal bearing operating with non-newtonian lubricant. Tribol Int 95: 221-235 (2016)

[13] Yu S S, Zhang S, Xia Z W, Liu S, Lu H J, Zeng X T. Textured hybrid nanocomposite coatings for surface wear protection of sports equipment. Surf Coat Technol 287: 76-81 (2016)

[14] Barnes C J, Childs T H C, Henson B, Southee C H. Surface finish and touch-A case study in a new human factors tribology. Wear 257: 740-750 (2004)

[15] Van Kuilenburg J, Masen M A, van der Heide E. The role of the skin microrelief in the contact behaviour of human skin: Contact between the human finger and regular surface textures. Tribol Int 65: 81-90 (2013)

[16] Klatzky R L, Pawluk D. Haptic perception of material properties and implications for applications. Proceedings of the IEEE 101: 2081-2092 (2013)

[17] Klatzky R L, Lederman S J. Tactile roughness perception with a rigid link interposed between skin and surface. Perception \& Psychophysics 61: 591-607 (1999)

[18] Skedung L, Danerlov K, Olofsson U, Johannesson C M, Aikala M, Kettle J, Arvidsson M, Berglund B, Rutland M W. Tactile perception: Finger friction, surface roughness and perceived coarseness. Tribol Int 44: 505-512 (2011) 
[19] Skedung L, Arvidsson M, Chung J Y, Stafford C M, Berglund B, Rutland M W. Feeling small: Exploring the tactile perception limits. Sci Rep 3: 1-6 (2013)

[20] Tomlinson S E, Carre M J, Lewis R, Franklin S E. Human finger contact with small, triangular ridged surfaces. Wear 271: 2346-2353 (2011)

[21] Veijgen N K. Skin friction: A novel approach to measuring in vivo human skin. PhD Thesis. University of Twente, Enschede, the Netherlands, 2013.

[22] Derler S, Huber R, Feuz H P, Hadad M. Influence of surface microstructure on the sliding friction of plantar skin against hard substrates. Wear 267(5-8): 1281-1288 (2009)

[23] Adams M J, Briscoe B J, Johnson S A. Friction and lubrication of human skin. Tribol Lett 26(3): 239-253 (2007)

[24] Duvefelt K, Olofsson U, Johannesson C M, Skedung L. Model for contact between finger and sinusoidal plane evaluate adhesion and deformation component of friction. Tribol Int 96: 389-394 (2016)

[25] Prodanov N, Gachot C, Rosenkanz A, Muchlich F, Muser M H. Contact mechanics of laser-textured surfaces. Tribol Lett 50: 41-48 (2013)

[26] Khodai M, Parvin N. Pressure measurement and some observation in lost foam casting. J Mater Process Technol 206(1-3): 1-6 (2008)

[27] Li J, Chen R, Ke W. Microstructure and mechanical properties of Mg-Gd-Y-Zr alloy cast by metal mould and lost foam casting. Transactions of Nonferrous Metals Society of China 21(4): 761-766 (2011)

[28] Ferro P, Fabrizi A, Cervo R, Carollo C. Effect of inoculant containing rare earth metals and bismuth on microstructure and mechanical properties of heavy-section near-eutectic ductile iron castings. J Mater Process Technol 213(9): 1601-1608 (2013)

[29] McGinley E L, Moran G P, Fleming G J P. Biocompatibility effects of indirect exposure of base-metal dental casting alloys to a human-derived three-dimensional oral mucosal model. Journal of Dentistry 41(11): 1091-1100 (2013)

[30] Li B, Ren M, Yang C, Fu H. Microstructure of Zn-A14 alloy microcastings bymicro precision casting based on metal mold. Transactions of Nonferrous Metals Society of China 18: 327-332 (2008)

[31] Adithyavairavan M, Subbiah S. A morphological study on direct polymer cast micro-textured hydrophobic surfaces. Surf Coat Technol 205: 4764-4770 (2011)

[32] Chao B, Cheng H, Nien L, Chen M, Nagao T, Li J, Hsueh C. Anti-reflection textured structures by wet etching and island lithography for surface-enhanced raman spectroscopy. Appl Surf Sci 357(A): 615-621 (2015)
[33] Chen W, Lin J, Hu G, Han X, Liu M, Yang Y, Wu Z, Liu Y, Zhang B. GaN nanowire fabricated by selective wet-etching of gan micro truncated-pyramid. Journal of Crystal Growth 426: 168-172 (2015)

[34] Kumar M D, Kim H, Kim J. Periodically patterned si pyramids for realizing high efficient solar cells by wet etching process. Solar Energy 117: 180-186 (2015)

[35] Jaeger R C. Introduction to Microelectronic Fabrication, 2 ed. Auburn, Upper Saddle River-Prentice Hall, 2002.

[36] Bauhuber M, Mikrievskij A, Lechner A. Isotropic wet chemical etching of deep channels with optical surface quality in silicon with hna based etching solution. Mater Sci Semiconduct Process 16: 1428-1433 (2013)

[37] Mondiali V, Lodari M, Chrastina D, Barget M, Bonera E, Bollani M. Micro and nanofabrication of $\mathrm{SiGe} / \mathrm{Ge}$ bridges and membrances by wet-anisotropic etching. Mciroelectr Eng 141: 256-260 (2015)

[38] Reshak A H, Shahimin M M, Shaar S, John N. Surface modification via wet chemical etching of single-crystalline silicon for photovoltaic application. Progress in Biophysics and Molecular Biology 113(2): 327-332 (2013)

[39] Lee Y, Kim H, Hussain S Q, Han S, Balaji N, Lee Y, Lee J, Yi J. Study of metal assisted anisotropic chemical etching of silicon for high aspect ratio in crystalline silicon solar cells. Mater Sci Semiconduct Process 40: 391-396 (2015)

[40] Faust J W, Palik E D. Study of the orientation dependent etching and initial anodizationg of $\mathrm{Si}$ in aqueous $\mathrm{KOH} . J$ Electrochem Soc 130: 1413-1420 (1983)

[41] Seidel H. The mechanism of anisotropic, electrochemical silicon etching in alkaline solutions. IEEE In Solid-State Sencor and Actuator Conference, 1990: 86-91.

[42] Linde H G, Austin L W. Catalytic control of anistropic silicon etching. Sensors and Actuators A 49: 181-185 (1995)

[43] Sheeja D, Tay B K, Yu Y J, Chua D H C, Milne W I, Miao J, Fu Y Q. Fabrication of amorphous carbon cantilever structures by isotropic and anisotropic wet etching methods. Diamond and Related Materials 12(9): 1495-1499 (2003)

[44] Lim C S, Hong M H, Senthil Kumar A, Rahman M, Liu $X$ D. Fabrication of concave micro lens array using laser patterning and isotropic etching. International Journal of Machine Tools \& Manufacture 46: 552-558 (2005)

[45] Freires de Queiroz J D, Maria de Sousa Leal A, Terada M, Agnez-Lima L F, Costa I, Cristhina de Souza Pinto N, Batistuzzo de Medeiros S R. Surface Modification by argon plasma treatment improves antioxidant defense ability of CHO-k1 cells on titanium surfaces. Toxicology in Vitro 28: 381-387 (2014) 
[46] Donnelly V M, Kornblit A. Plasma etching: Yesterday, today, and tomorrow. Journal of Vacuum Science \& Technology A 31(5): 1-48 (2013)

[47] Coburn J W, Winters H F. Plasma etching-A discussion of mechanisms. Journal of Vacuum Science \& Technology 16: 391 (1979)

[48] Davidse P D. RF sputter etching-A universal etch. Journal of Electrochemical Society: Solid State Science 116(1): 100-103 (1969)

[49] Hosokawa N, Matsuzaki R, Asamaki T. RF sputter-etching by fluoro-chloro-hydrocarbon gases. Japanese Journal of Applied Physics 13: 435-438 (1974)

[50] Aizawa T, Fukuda T. Oxygen Plasma etching of diamondlike carbon coated mold-die for micro-texturing. Surf Coat Technol 215: 364-368 (2013)

[51] 3D Systems Inc. Company set up for stereolithography. CAD in Industry 19(4): 223 (1987)

[52] Sachs E, Cima M, Cornie J, Brancazio D, Bredt J, Curodeau A, Fan T, Khanuja S, Lauder A, Lee J, Michaels $\mathrm{S}$. Three-dimensional printing; the physics and implications of additive manufacturing. CIRP Annals-Manufacturing Technology 42(1): 257-260 (1993)

[53] Lam C X F, Mo X M. Scaffold development using 3D printing with a starch-based polymer. Materials Science \& Engineering, C: Biomimetic and Supramolecular Systems $C$ 20(1-2): 49-56 (2002)

[54] Moon J, Caballero J E. Ink-jet printing of binders for ceramic components. Journal of the American Ceramic Society 85(4): 755-762 (2002)

[55] Seitz H, Rieder W. Three-dimensional printing of porous ceramic scaffolds for bone tissue engineering. Journal of Biomedical Materials Research, Part B, Applied Biomaterials 74(2): 782-788 (2005)

[56] Utela B, Storti D, Anderson R, Ganter M. A review of process development steps for new material systems in three dimensional printing (3DP). J Manufact Process 10: 96-104 (2008)

[57] Han Y, Wei C, Dong J. Super-resolution electrohydrodynamic (EHD) 3D printing of micro-structures using phase-change inks. Manufact Lett 2: 96-99 (2014)

[58] Dunn A, Wlodarczyk K L, Carstensen J V, Hansen E B, Gabzdyl J, Harrison P M, Shephard J D, Hand D P. Laser surface texturing for high friction contacts. Applied Surface Science 357(B): 2313-2319
[59] Kurella A, Dahotre B N. Review paper: Surface modification for bioimplatns: The role of laser surface engineering. Journal of Biomaterials Applications 20: 5-50 (2005)

[60] Wang Y, Yang H, Hao J, Han Q, Fang L, Ge S. Experiment research on fabrication \& wettability of micro- and nanoscale surface textured by ultrafast laser. Lasers In Engineering 21(3-4): 241-254 (2011)

[61] Kumari R, Scharnweber T, Pfleging W, Besser H, Majumdar J D. Laser Surface textured titanium alloy (Ti-6Al-4V)—Part II-Studies on bio-compatibility. Appl Surf Sci 357(A): 750-758 (2015)

[62] Wong RCP, Hoult AP, Kim JK, Yu TX. Improvement of adhesive bonding in aluminium alloys using a laser surface texturing process. J Mater Process Technol 63: 579-584 (1997)

[63] Geiger M, Roth S, Becker W. Influence of laser-produced microstructures on the tribological behavior of ceramics. Surf Coat Technol 100-101: 17-22 (1998)

[64] Geiger M, Popp U, Engel U. Eximer laser micro texturing of cold forging tool surface-influence on tool life. CIRP Annals 51: 231-234 (2002)

[65] Wang X, Kato K, Adachi K, Aizawa K. The effect of laser texturing of SiC surface on the critical load for the transition of water lubrication mode from hydrodynamic to mixed. Tribol Int 34(10): 703-711 (2001)

[66] Kovalchenko A, Ajayi O, Erdemir A, Fenske G, Etsion I. The Effect of laser texturing of steel surfaces and speedload parameters on the transition of lubrication regime from boundary to hydrodynamic. Tribol Trans 47(2): 299-307 (2004)

[67] Kovalchenko A, Ajayi O, Erdemir A, Fenske G, Etsion I. The effect of laser surface texturing on transitions in lubrication regimes during unidirectional sliding contact. Tribol Int 38(3): 219-225 (2005)

[68] Van Kuilenburg J, Masen M A, Groenendijk M N W, Bana V, van der Heide E. An experimental study on the relation between surface texture and tactile friction. Tribol Int 48: 15-21 (2012)

[69] Van der Heide E, Saenz de Viteri V, Rodringuez-Vidal E, Pagano F, Wadman B, Wiklund D, Matthews D T A, Contreras Fortes J, Zhang S. Steel sheet surfaces with enhanced tactile feel. European Commission Research Programme of the Research Fund for Coal and Steel, RFSR-CT-2011-00022, 2011-2014. 


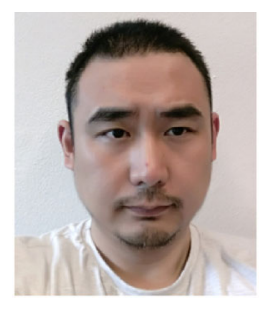

Sheng ZHANG. He received his bachelor degree in mechanical engineering in 2008 from California State University, Fresno, USA, and obtained his Ph.D degree in mechanical engineering at University of

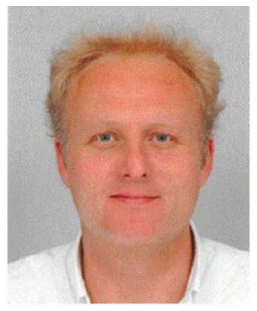

Emile VAN DER HEIDE. He obtained his M.S. and Ph.D degrees in mechanical engineering from University of Twente in 1995 and 2002. His current position is a professor, chair of Skin Tribology,
Twente, Enschede, the Netherlands. He has recently joined the State Key Laboratory of Tribology in Tsinghua University as a post-doctoral researcher in 2016. His research interests include bio-tribology and surface texture design.

Laboratory for Surface Technology and Tribology, Faculty of Engineering Technology, University of Twente. He has received President's International Fellowship 2016/17 from Chinese Academy of Sciences. His research areas cover the surface engineering, biotribology and contact mechanics. 